\title{
MEDIDAS LABORALES Y DE SEGURIDAD SOCIAL EN EL CONTEXTO COVID: UN BALANCE DE MAYO DE 2020 A MAYO DE 2021*
}

\author{
Iván Antonio RodRíGUEz CARDO \\ Profesor Titular de Derecho \\ del Trabajo y de la Seguridad Social \\ Universidad de Oviedo \\ Experto Nacional en la European \\ Labour Law Network \\ rodriguezivan@uniovi.es
}

\section{INTRODUCCIÓN}

El coronavirus Covid-19 ha provocado una pandemia cuyas repercusiones transcienden del ámbito de la salud pública. La enfermedad causada por el virus ha modificado incluso hábitos de comportamiento social, conductas individuales y, en último término, la forma de relacionarse entre las personas. Por supuesto, el ordenamiento jurídico ha sufrido modificaciones notables para tratar de minimizar el impacto de la enfermedad. Las reformas normativas no se han limitado al ámbito de la salud pública y no solo se ha visto afectado el Derecho de naturaleza puramente administrativa, que desde luego ha de contar con un papel protagonista en un escenario donde los poderes de la Administración se incrementan de tal manera que limitan notablemente los derechos fundamentales atendiendo a la tutela de bienes de mayor calado, como la vida y la salud.

Es evidente que determinadas restricciones afectan a la actividad industrial y comercial, y con ello a la economía y al trabajo, lo que obliga a adoptar un marco normativo específicamente diseñado para este nuevo escenario. Una primera aproximación a esas normas fue publicada en esta misma revista Foro, y en concreto en el núm. 2/2019 (pp. 279-298), con el fin de ofrecer una primera aproximación a las novedades introducidas durante los dos primeros meses de vigencia del estado de alarma, y en concreto hasta 30 de abril de 2020. Como se recordará, fueron dos meses complejos en los que se sucedieron normas de muy diverso alcance y signifi-

\footnotetext{
* Trabajo cerrado a 20 de mayo de 2021.
} 
cado, y sin que resultara muy evidente si esas nuevas reglas tenían alcance meramente coyuntural o nacían con vocación de permanencia.

Un año después algunos de los interrogantes que por entonces se planteaban ya tienen respuesta, pero otros muchos continúan aletargados hasta el momento, y a buen seguro se suscitarán dudas y dificultades novedosas a corto o medio plazo. Precisamente por ello, conviene volver a detenerse en las medidas que se han ido implementando a lo largo de estos meses con el fin de reducir el impacto de la pandemia sobre el mercado de trabajo, y en particular las que tienen como fin la protección de los trabajadores. El propósito, así pues, consiste en complementar y actualizar el estudio publicado en esta misma revista el año pasado dando cuenta de las novedades acontecidas y tratando de ofrecer alguna respuesta con vocación de futuro.

Como es sabido, el primer estado de alarma se inició con el Decreto $463 / 2020$, de 14 de marzo, y fue prorrogado en seis ocasiones, concluyendo el 21 de junio de 2020. Sin embargo, el final de esa particular situación no se debió a la erradicación ni del virus ni de la enfermedad, sino que entraron en juego otros muchos factores, y el deterioro de la economía no fue una razón menor. De ahí que la conclusión del estado de alarma no conllevara un retorno pleno al contexto previo, sino que fue el comienzo de otra etapa, calificada eufemísticamente como «nueva normalidad», caracterizada por el mantenimiento de muchas restricciones y obligaciones (uso de mascarilla, distancia de seguridad, limitaciones de aforos, etc.) y una amenaza latente de medidas más severas ante la eventualidad de nuevos brotes.

Esa amenaza se consumó en octubre de 2020, ya que ante el notable aumento de positivos — y de fallecidos- el Real Decreto 926/2020, de 25 de octubre, declaró nuevamente el estado de alarma, aunque con una configuración muy diferente a la de marzo y con una duración mucho más extensa, pues finalizó el 9 de mayo de 2021. Durante ese periodo se evitaba en primera instancia el confinamiento de la población y se descentralizaba la toma de decisiones, de modo que cada comunidad autónoma pudiera valorar en su ámbito concreto qué medidas resultaban las más pertinentes, aunque el confinamiento perimetral, las restricciones a las reuniones (en ámbitos públicos y privados) y la «limitación de la libertad de circulación de las personas en horario nocturno» (el denominado «toque de queda») se convirtieron en las acciones más habituales, pues se consideraba que podían reducir la propagación de la enfermedad sin perjudicar excesivamente la economía. Sin embargo, muchas comunidades autóno- 
mas decidieron asimismo el cese de la actividad no esencial, fundamentalmente comercial y de ocio, lo que unido a las restricciones a la movilidad y a las reuniones provoca una afectación importante al entramado económico. Algunas actividades ni siquiera se reanudaron con el final de ese segundo estado de alarma ( $v$. gr., ocio nocturno).

Con la perspectiva del tiempo, parece claro que las medidas de corte social y laboral aprobadas en el contexto de la pandemia pueden dividirse en varios bloques, principalmente en cuatro. En primer lugar, todas aquellas dirigidas a adaptar la organización de la actividad laboral, la prestación de servicios, en definitiva, al nuevo contexto, con la preferencia por el teletrabajo como principal manifestación. En segundo lugar, las que tienen como fin contribuir a la subsistencia de las empresas y colaborar con ellas para que puedan continuar desarrollando su actividad con la mayor productividad posible (ERTEs). En tercer lugar, las destinadas a proteger a los trabajadores en esta particular coyuntura, un grupo de medidas heterogéneas que se agrupan en lo que desde determinados ámbitos políticos se ha dado en llamar «escudo social» (prohibición de despedir, cláusula de salvaguarda y mejora de la acción protectora de la Seguridad Social). Y, en último lugar, las que vienen motivadas específicamente por la incidencia directa del Covid (no del contexto creado por la pandemia), como la protección de los trabajadores que han contraído la enfermedad o las reglas de carácter profesional en sectores especialmente sensibles, como la sanidad. El propósito del presente estudio consiste, precisamente, en dar cuenta de las medidas de índole laboral y de Seguridad Social que se adoptaron desde mayo de 2020 hasta mayo de 2021, ofreciendo una primera aproximación a su alcance y significado, sin perjuicio de que muchos de sus efectos y problemas no se podrán valorar plenamente hasta dentro de cierto tiempo, toda vez que la pandemia no ha concluido.

\section{LA ADAPTACIÓN DE LA PRESTACIÓN DE SERVICIOS PARA COMBATIR LA PROPAGACIÓN DEL COVID: LA INTENSIFICACIÓN DEL TELETRABAJO}

La emergencia sanitaria ha exigido modificaciones en la forma de prestación de servicios profesionales que no tienen como objetivo una mejora de la productividad de las empresas, sino reducir la probabilidad de contagios. En efecto, determinadas medidas preventivas se han implementado con carácter general, y alcanzan también al ámbito del trabajo, a modo de 
imposiciones legales que, por motivos de salud, desbordan las facultades, derechos y obligaciones de empresarios y trabajadores. De manera análoga a lo que en su día sucediera con la prohibición de fumar en el trabajo, el empleador debe ahora asegurarse de que sus trabajadores —así como sus clientes y usuarios - respeten ciertas reglas de salud pública dirigidas, precisamente, a reducir el riesgo de transmisión del Covid, como sucede con la utilización de mascarillas, la intensificación de hábitos de higiene o el respeto de la «distancia social» 1 .

Se trata, en todos los casos, de exigencias legales que pueden contar con importantes consecuencias de índole laboral, en particular porque su incumplimiento podría desembocar en sanciones disciplinarias, inclusive el despido. Es más, en algún ámbito, como el de los medios de comunicación, se han producido extinciones contractuales por comportamientos extralaborales poco edificantes, decisiones jurídicamente discutibles, pero cuyo análisis excede del propósito de este estudio.

Sin lugar a dudas, la novedad más relevante en relación con la organización del trabajo consiste en la incentivación, con expresa declaración legal de preferencia en ciertos momentos, del trabajo a distancia, en la modalidad de teletrabajo. En el ya mencionado artículo publicado en el núm. 2 de 2019 de esta misma revista se dejó constancia de esa opción legal, vinculada por supuesto al confinamiento de la población y al propósito de reducir en lo posible la movilidad.

La preferencia por el teletrabajo era comprensible, pero su articulación jurídica no resultaba sencilla por la inadecuación del art. 13 ET. Esas fricciones de alguna manera se han dulcificado con la aprobación de un nuevo marco jurídico específico, el Real Decreto-ley 28/2020, de 22 de septiembre, de trabajo a distancia (sustituido posteriormente por la Ley 10/2021, de 9 de julio), que procedió a vaciar de contenido el art. 13 ET, pues en la actualidad únicamente remite a esa nueva norma. En el ámbito público, el Estatuto Básico del Empleado Público fue modificado por el Real Decreto Ley 29/2020, de 29 de septiembre, recogiendo una regulación del «teletrabajo» en su nuevo art. 47 bis.

Sin pretensión de efectuar un análisis detenido del régimen jurídico del trabajo a distancia, sí conviene poner de manifiesto que no es una regulación en la que encaje cualquier prestación de servicios en un lugar elegido por el trabajador, sino que deben realizarse dos precisiones. En pri-

${ }^{1}$ Vid. art. 7 de la Ley 2/2021, de 29 de marzo, de medidas urgentes de prevención, contención y coordinación para hacer frente a la crisis sanitaria ocasionada por el Covid-19. 
mer lugar, y como regla general, la norma únicamente afecta al trabajo que se desarrolle a distancia «con carácter regular», entendiéndose por tal un mínimo del 30 por 100 de la jornada. En segundo lugar, y de manera muy significativa, la disposición transitoria tercera del Real Decretoley 28/2020 excluye de su ámbito de aplicación el «trabajo a distancia implantado excepcionalmente en aplicación del art. 5 del Real Decretoley 8/2020, de 17 de marzo, o como consecuencia de las medidas de contención sanitaria derivadas del Covid-19», porque, «mientras estas se mantengan, le seguirá resultando de aplicación la normativa laboral ordinaria».

Por consiguiente, y es desde luego muy relevante, coexisten dos regímenes jurídicos distintos para el trabajo a distancia. Por un lado, el ordinario o general, que se caracteriza por su voluntariedad y que debe ser plasmado en un acuerdo entre empresario y trabajador en los términos de la norma aprobada en septiembre de 2020. Por otro, el excepcional, derivado de la pandemia y amparado por el art. 5 del Real Decreto-ley 8/2020, al que «le seguirá resultando de aplicación la normativa laboral ordinaria», sin perjuicio de que «las empresas estarán obligadas a dotar de los medios, equipos, herramientas y consumibles que exige el desarrollo del trabajo a distancia, así como al mantenimiento que resulte necesario» y de que la «negociación colectiva establecerá la forma de compensación de los gastos derivados para la persona trabajadora de esta forma de trabajo a distancia, si existieran y no hubieran sido ya compensados» ${ }^{2}$.

Llama poderosamente la atención que una norma aprobada el 22 de septiembre de 2022 contemple una fórmula que nació durante el primer estado de alarma y cuya vigencia, teóricamente, concluía tres meses después de finalizar esa particular situación (art. 15 del Real Decretoley 15/2020). Como se dijo, el estado de alarma declarado en marzo concluyó el 21 de junio, de modo que el 21 de septiembre la preferencia por el teletrabajo dejaba de ser operativa. En teoría, a partir de ese momento no cabría imponer el teletrabajo sobre la base del art. 5 del Real Decretoley $8 / 2020$, lo que obliga a una lectura generosa de la disposición transitoria tercera de la Ley 10/2021.

En este sentido, ese precepto no solo permitiría la continuidad del teletrabajo decidido al amparo de la normativa de marzo, sino también nuevas imposiciones de esa forma de prestación de servicios que sean «consecuencia de las medidas de contención sanitaria derivadas del Covid-19,

2 Vid. J. Thibault Aranda, «Toda crisis trae una oportunidad: el trabajo a distancia», Trabajo y Derecho, monográfico núm. 12 (2020), disponible en www.smarteca.es. 
y mientras estas se mantengan». Jurídicamente es una opción normativa muy cuestionable, pues no se limitaría a permitir la continuidad del teletrabajo allí donde se hubiera articulado, sino que facultaría a los empresarios para adoptar dicha medida en el futuro sobre una base no demasiado sólida. Téngase en cuenta que esta fórmula es una excepción a la regla general — que exige voluntariedad-y que, por tanto, merece una interpretación restrictiva, y pese a ello la citada disposición transitoria tercera no impone plazos, límites o condiciones, sino que remite genéricamente a las «medidas de contención sanitaria». Por consiguiente, las decisiones empresariales en ese sentido podrán ser objeto de revisión judicial para comprobar no solo si se cumplen los requisitos pertinentes para la imposición en contra de la voluntad del trabajador, sino también para perfilar la duración y las condiciones en las que tales servicios deben prestarse. Todo ello sin olvidar que la peculiar configuración del segundo estado de alarma decidida en octubre de 2020 ha conducido a que algunas comunidades autónomas apuesten por el teletrabajo, al menos en el ámbito de la administración pública, lo que obligará a plantear el debate en términos de competencias constitucionales para determinar cuándo actúan como administración y cuándo como empleador, y, en el primero de los casos, si las medidas adoptadas con finalidad sanitaria prevalecen sobre la distribución de competencias en materia laboral recogida en el art. 149.1.7 de la Constitución ${ }^{3}$.

Como se aprecia, son cuestiones jurídicas de envergadura que se han visto desplazadas, y prácticamente sepultadas, por consideraciones más pragmáticas en un contexto donde la prioridad consiste en minimizar el impacto de la pandemia. Sin embargo, a buen seguro se plantearán en un futuro cercano, donde, en primer lugar, habrá que diferenciar entre meras «recomendaciones» de la administración autonómica y decisiones en sentido estricto, y, en segundo lugar, habrá de valorarse la actuación de cada empresa individualmente y las razones que hayan motivado la decisión del teletrabajo, las condiciones de ejecución y su duración.

Con todo, las dudas seguirán produciéndose, pues aun aceptando que la disposición transitoria tercera de la Ley 10/2021 admite la imposición del teletrabajo por causa Covid, será menester determinar cuál es el régimen jurídico concreto de esa prestación de servicios, máxime cuando el

3 Vid. I. A. Rodríguez CARDo, «El teletrabajo en la Administración Pública», en J. GaRCía Murcia (dir.), Contrato de trabajo y relación laboral en el ámbito de las Administraciones Públicas, Madrid, MTES, 2021, pp. 152 y ss. 
precepto remite a la «normativa laboral ordinaria». Conviene tener presente que el art. 5 del Real Decreto-ley 8/2020 introducía una peculiaridad en materia de prevención de riesgos laborales, ya que, «con el objetivo de facilitar el ejercicio de la modalidad de trabajo a distancia en aquellos sectores, empresas o puestos de trabajo en las que no estuviera prevista hasta el momento, se entenderá cumplida la obligación de efectuar la evaluación de riesgos, en los términos previstos en el art. 16 de la Ley 31/1995, de 8 de noviembre, de Prevención de Riesgos Laborales, con carácter excepcional, a través de una autoevaluación realizada voluntariamente por la propia persona trabajadora». Ese art. 5 ha sido formalmente derogado y, en cualquier caso, no parece que pueda ser considerado como parte integrante de la «normativa laboral ordinaria», pese a que su cumplimiento podría resultar muy conveniente para todos los sujetos implicados, particularmente en situaciones de restricciones severas de movilidad. A la postre, esta normativa de emergencia se caracteriza por su carácter aluvional y una muy deficiente coordinación de unas normas con otras, lo que da lugar a un marco jurídico complejo y que requiere arduos esfuerzos para su correcta articulación.

Por otro lado, todas estas variaciones sobrevenidas de las condiciones de trabajo, no planificadas y seguramente tampoco queridas ni por empresarios ni por trabajadores, han provocado un impacto notable en las dinámicas familiares. El art. 37 del Estatuto de los Trabajadores concede al trabajador el derecho a solicitar, y ver aceptadas, ciertas adaptaciones o modificaciones del tiempo de trabajo para poder atender responsabilidades familiares. Esas reglas fueron complementadas durante el estado de alarma por otras más coyunturales contenidas en el art. 6 del Real Decreto-ley 8/2020, que ampliaba los derechos de conciliación cuando el trabajador podía demostrar nuevas necesidades familiares provocadas por el Covid, entre las que se mencionaban el cierre de guarderías o centros educativos o el cese (temporal o definitivo) de la actividad de cuidadores profesionales de personas dependientes, situaciones en las que el trabajador debía asumir directamente esas labores de atención, con la consiguiente dificultad para cumplir sus obligaciones laborales con la misma diligencia.

La norma remitía en estos casos a un acuerdo entre empresario y empleado en orden a implementar una medida proporcional que permitiera compatibilizar el trabajo con las nuevas responsabilidades familiares, y a tal fin se sugería un catálogo de posibilidades: «cambio de turno, alteración de horario, horario flexible, jornada partida o continuada, cambio 
de centro de trabajo, cambio de funciones, cambio en la forma de prestación del trabajo, incluyendo la prestación de trabajo a distancia, o en cualquier otro cambio de condiciones que estuviera disponible en la empresa o que pudiera implantarse de modo razonable y proporcionado, teniendo en cuenta el carácter temporal y excepcional de las medidas contempladas en la presente norma, que se limita al periodo excepcional de duración del Covid-19». Estas medidas de conciliación específicamente vinculadas a la pandemia recibieron el nombre de «Plan MECUIDA» a partir del Real Decreto-ley 15/2020, de 21 de abril, y su vigencia ha sido prorrogada en varias ocasiones, la última hasta 28 de febrero de 2022 (DA 9. ${ }^{a}$ del Real Decreto-ley 18/2021).

\section{LA POTENCIACIÓN DE LA FLEXIBILIDAD INTERNA A TRAVÉS DE LOS ERTES COMO ALTERNATIVA AL DESPIDO}

El teletrabajo permite mitigar algunos de los efectos laborales de la pandemia, pero no es una opción operativa en todos los sectores productivos y profesiones, ni tampoco necesariamente la más eficiente. Los cambios en la organización del trabajo pueden contar con más variantes y las normas aprobadas durante el estado de alarma incrementaron - e incentivaron- mecanismos de flexibilidad interna. Conviene tener presente que estas normas, concebidas fundamentalmente en marzo de 2020, tenían como principal finalidad contribuir a que las empresas pudieran superar sin demasiados perjuicios una coyuntura que en apariencia se estimaba de breve duración. En efecto, se diseñaron medidas que se entendían muy eficaces para afrontar un cese de actividad o una reducción significativa de la producción, que en esos momentos se estimaba que no superaría unas pocas semanas, de modo que la actividad se podría retomar al pleno rendimiento en un corto espacio de tiempo.

En este contexto, el papel protagonista en la adaptación de la organización del trabajo ha correspondido a un instrumento que cabría denominar ERTE Covid, esto es, expedientes de regulación temporal de empleo por causa del Covid, cuyo propósito consiste en facilitar una reconfiguración de las condiciones de trabajo precisamente para evitar la destrucción de empleo. En verdad, las normas aprobadas durante el estado de alarma que comenzó en marzo de 2020 dieron paso a un ordenamiento laboral paralelo que convive con el Derecho del Trabajo estructural, pero que 
se dirige específicamente a paliar las consecuencias de la pandemia en el mercado de trabajo ${ }^{4}$.

${ }^{4}$ La doctrina científica ha analizado profundamente las normas aprobadas durante el estado de alarma. Entre las publicaciones más destacadas pueden mencionarse las siguientes: V. ÁlvareZ GARCÍA, «El coronavirus (Covid-19): respuestas jurídicas frente a una situación de emergencia sanitaria», y A. NOGUEIRA LÓPEZ, «Confinar el coronavirus. Entre el viejo Derecho sectorial y el Derecho de excepción», ambas en El Cronista, núm. 86-87 (2020); I. AlzAga RuIZ, «El despido del trabajador por falta de adaptación a las modificaciones técnicas en su puesto de trabajo», Revista de Derecho Social, núm. 55 (2011); C. ArAGÓN Gómez (coord.), Impacto del Covid-19 en materia laboral y de Seguridad Social, Madrid, Francis Lefebvre, 2020; C. ARAGÓN GÓMEZ, «El Covid-19 como riesgo causante de prestaciones de Seguridad Social»; I. BeLtrÁn DE HeREdia Ruiz, «Covid-19 y expediente de regulación temporal de empleo por fuerza mayor»; M. ${ }^{a}$ E. CASAS BAAMONDE y M. RodRíGuez-PiñERO Y BRAVO-FERRER, «Un nuevo Derecho del Trabajo en la emergencia. Las medidas laborales y de seguridad social en el estado de alarma declarado por la crisis sanitaria del coronavirus Covid-19» y «Nueva prórroga del estado de alarma y nuevas reformas laborales y de Seguridad Social (RDL 15/2020)»; J. CRUZ VILLALÓN, «Teletrabajo y coronavirus: de la emergencia a la permanencia»; J. LAHERA FORTEZA, «Flexiseguridad laboral ante la crisis del coronavirus»; J. M. Miranda Boto, «¿Esperando a Grouchy? El papel de la Unión Europea en la crisis del Covid-19»; D. Pérez Del Prado, «La protección por desempleo ante la crisis del coronavirus»; S. RODRÍGUEZ EsCANCIANO, «Medidas para la conciliación de la vida laboral y familiar ante la emergencia sanitaria por Covid-19», y E. Rojo TORRECILLA, «Emergencia sanitaria y legislación laboral. ¿Qué respuestas a la crisis? Un primer análisis de la normativa dictada en España», todas en Derecho de las Relaciones Laborales, núm. 4 (2020); M. BASTERRA HERNÁNDEZ, «La falta de adaptación a las modificaciones técnicas operadas en el puesto de trabajo como causa del despido objetivo», en AAVV, La extinción del contrato de trabajo: Perspectiva comparada de las regulaciones italiana y española, Valencia, Tirant lo Blanch, 2016; M. ${ }^{a}$ E. CASAS BAAMONDE, «Nuevas medidas laborales y de seguridad social, extraordinarias y temporales, tras la finalización del estado de alarma y el proceso de "desescalada"», Diario La Ley, núm. 9677 (2020); J. CoRDERo GonzÁlez, «Estado de alarma por la Covid19 y su impacto en el marco normativo laboral español», Trabajo y Derecho, núm. 65 (2020); M. A. Falguera Baró, «Análisis de urgencia de la legislación laboral durante el estado de alarma por el Covid-19», Ciudad del Trabajo, suplemento (2020); J. A. FernándEZ Avilés, «Es suficiente este Derecho laboral excepcional "por aluviones" frente a la pandemia del Covid-19?», y E. E. TALÉNS VISCONTI, «Análisis de las medidas de Seguridad Social adoptadas por el Gobierno de España en relación con la crisis del Covid-19», ambas en RTSS (CEF), núm. 445 (2020); F. FItA OrTEgA, «Las medidas laborales frente al Covid-19 desde una perspectiva de género», Diario la Ley, núm. 9623 (2020); C. GALA Durán, «Las medidas adoptadas en materia de Seguridad Social y conciliación de la vida laboral y familiar en relación con la crisis del coronavirus Covid-19», La Administración Práctica, núm. 5 (2020); J. Lahera Forteza y R. Mateo Escobar, Políticas para mitigar el impacto laboral y social del Covid-19 en el periodo de transición, Barcelona, ESADE, 2020, disponible en bttps://www. esade.edu/itemsweb/research/EsadeEcPol_InDepth_Politicas_mitigacion.pdf; J. L. MONEREO PÉREZ, «Principio de igualdad y despido por ineptitud o discapacidad: la protección garantista multinivel», Lex Social: revista de los derechos sociales, núm. 1 (2019); W. SANGUINETI RAYMOND, «El Derecho del trabajo español de la emergencia sanitaria», Revista General de Derecho del Trabajo y de la Seguridad Social, núm. 56 (2020), disponible en www.iustel.com; J. M. Servais, El Covid-19. ¿Qué nos dice la OIT?, disponible en http://www.cielolaboral. com/wp-content/uploads/2020/04/oit_noticias_cielo_coronavirus.pdf, y F. VILA TIERNO, La respuesta normativa a la crisis laboral por el Covid-19, Murcia, Laborum, 2020. 
En concreto, los ERTEs tienen como finalidad sustituir las extinciones de contratos por medidas menos traumáticas, como la suspensión de la relación laboral o la reducción de jornada, lo que implica un ahorro temporal de costes para el empresario en forma de salario y también, en este caso concreto, de cotizaciones a la Seguridad Social. Ese fue uno de los principales propósitos del Real Decreto-ley 8/2020, de 17 de marzo, que incluyó reglas particulares para agilizar la tramitación de los ERTEs (tanto los de fuerza mayor como los de causa económica, técnica, organizativa o de producción, en adelante ETOP), norma que aún está en vigor, si bien ha sido modificada en varias ocasiones para adaptar su contenido a los nuevos escenarios.

En un primer momento, y como se sabe, se potenciaron especialmente los ERTEs Covid por fuerza mayor regulados en el art. 22 del Real Decretoley $8 / 2020$, puesto que, como premisa de partida, se entendía que el impacto del virus resultaría breve en el tiempo y que únicamente era necesario articular medidas que permitieran superar una problemática coyuntural de duración muy limitada, no mayor de dos semanas (la extensión prevista inicialmente para el estado de alarma) o un mes a lo sumo. Esa norma calificó la pandemia como un supuesto particular de fuerza mayor para evitar dificultades por su dudoso encaje en el art. 47 del Estatuto de los Trabajadores (que no fue modificado a estos efectos), y no solo facilitaba la adopción de las medidas correspondientes, sino que esta clase de ERTEs disfrutaba de una reducción de cuotas de cotización (exoneraciones en la terminología de la norma). Los efectos de la pandemia se prolongaron, y con ello los ERTEs se generalizaron y sus efectos se prorrogaron no solo por causa de fuerza mayor, sino que también se admitieron ERTEs Covid por causas económicas, técnicas, organizativas o de producción, a los que se extendieron las reducciones de cuotas a la Seguridad Social a partir del 27 de junio de 2020 con la entrada en vigor del Real Decreto-ley 24/20205.

Los ERTEs Covid se han erigido en el pilar básico de los procesos de reorganización de la actividad empresarial, gracias a que permiten un ahorro de costes que ha facilitado la subsistencia de muchas empresas. Cierto es que el régimen jurídico de esos instrumentos ha ido variando, pues su fisonomía no ha sido exactamente la misma en origen que a partir del 27

5 Vid. A. DE la Puebla Pinilla, «Cuestiones problemáticas en torno a los expedientes de regulación temporal de empleo de la emergencia sanitaria Covid-19», Trabajo y Derecho, monográfico núm. 12 (2020), disponible en www.smarteca.es, y P. MenÉNDEz SeBASTIÁN, Facultades extintivas del empresario en la era Covid, Valencia, Tirant lo Blanch, 2021, pp. 25 y ss.. 
de junio de 2020 con el Real Decreto-ley 24/2020 o tras los Reales Decretos-ley 30/2020, de 30 de septiembre; $2 / 2021$, de 26 de enero; 11/2021, de 27 de mayo, o 18/2021, de 28 de septiembre, pero lo cierto es que, con algunos matices en relación con el procedimiento, las causas concretas y el alcance de las bonificaciones (con eventuales diferencias sectoriales), los ERTEs se han ido autorizando, negociando o prorrogando (según los casos) hasta el 28 de febrero de 2022, pues ha sido la única manera de evitar una fuerte destrucción de empleo hasta el momento, máxime en un contexto de elevada incertidumbre económica y sanitaria (lo que justifica, por ejemplo, la específica previsión del «rebrote» o «impedimento» como causa para el ERTE).

En suma, los ERTEs se han convertido en la piedra angular de toda esta regulación, en consonancia con la prioridad de las medidas de flexibilidad interna sobre las extinciones de contratos. Ese propósito se traduce en tres reglas de notable interés. La primera se contiene en el art. 2 del Real Decreto-ley 9/2020, de 27 de marzo, y se ha dado en llamar «prohibición de despedir». Ese precepto dispone, concretamente, que «la fuerza mayor y las causas económicas, técnicas, organizativas y de producción» relacionadas con el Covid no son «justificativas de la extinción del contrato de trabajo ni del despido». A pesar de la denominación —-mediática-, esa limitación no conforma una verdadera prohibición de despido, sino más bien supone la desactivación de una causa legal de extinción como instrumento para derivar la situación hacia medidas de flexibilidad interna, y en particular hacia reducciones de jornada y suspensiones de contratos, precisamente los ERTE, en la línea que ha propuesto la $\mathrm{OIT}^{6}$. Esa limitación a las facultades empresariales ha extendido su vigencia hasta el 28 de febrero de 2022, aunque desde luego el contexto al que debía aplicarse inicialmente no es el actual y seguramente el concepto de «causas relacionadas con el Covid» es ya diferente.

La segunda se recoge en el art. 5 de la Ley 3/2021 (que proviene del Real Decreto-ley 9/2020), también con vigencia extendida hasta el 28 de febrero de 2022, y se dirige a la protección de los trabajadores temporales, pues la duración de esos contratos (incluidos los formativos, de relevo e interinidad) se interrumpe en tanto se encuentran suspendidos en virtud de un ERTE Covid. La norma crea una suerte de paréntesis, de modo que los contratos de duración determinada no pueden llegar a término durante el periodo de suspensión, sino que «hibernan» en

${ }^{6}$ bttps://www.ilo.org/global/topics/coronavirus/impacts-and-responses/lang--en/index.btm. 
ese intervalo y se reanudan una vez que el trabajador se reincorpora a la actividad ${ }^{7}$.

Y la tercera es la denominada cláusula de salvaguarda, que se traduce en la obligación de las empresas que han intentado superar la crisis beneficiándose de un atractivo régimen de exoneraciones de cuotas a la Seguridad Social a través de ERTEs de mantener el empleo durante al menos seis meses tras la reanudación de la actividad. Por tanto, esta cláusula de salvaguarda, a diferencia de la «prohibición de despedir», carece de alcance general, pues solo nace para empresas que hayan tramitado un ERTE Covid y que gracias al mismo hayan disfrutado de una reducción de las cotizaciones. De ahí que en una primera etapa, y en concreto hasta la entrada en vigor del Real Decreto-ley 24/2020, de 26 de junio, este compromiso de mantenimiento del empleo únicamente afectaba a las empresas que habían tramitado un ERTE Covid por fuerza mayor, pero no un ERTE ETOP, ya que estos no disfrutaron de exoneraciones de cuotas hasta la entrada en vigor del Real Decreto-ley 24/2020. La cláusula de salvaguarda pervivirá en tanto lo hagan los ERTEs Covid y su duración en el tiempo implica que una misma empresa puede concatenar cláusulas de salvaguarda si se ha beneficiado de varios ERTEs Covid ${ }^{8}$.

\section{LA SEGURIDAD SOCIAL COMO PARTE ESENCIAL DEL DENOMINADO «ESCUDO SOCIAL»: UN ALUVIÓN DE MEDIDAS COYUNTURALES Y EL INGRESO MÍNIMO VITAL COMO PRESTACIÓN ESTRUCTURAL Y DE CIERRE DEL SISTEMA DE SEGURIDAD SOCIAL}

La Seguridad Social, sin género de dudas, ha jugado un papel decisivo durante la crisis provocada por el Covid. Al margen de los debates sobre su configuración futura para garantizar la viabilidad a largo plazo y que han desembocado en nuevas recomendaciones del Pacto de Toledo, el Gobierno introdujo medidas concretas para afrontar las consecuencias de la pandemia ${ }^{9}$. En perspectiva, esas actuaciones pueden dividirse

\footnotetext{
7 Esta ventaja se extendió, asimismo, a los profesores universitarios y a los investigadores con un contrato no indefinido. Vid. DDAA 12. ${ }^{a}$ y 13. ${ }^{a}$ del Real Decreto-ley 11/2020.

${ }^{8}$ Vid. P. Menéndez Sebastí́n e I. A. Rodríguez Cardo, «Límites al despido por Covid: alcance y significado de la "prohibición de despedir" y la cláusula de salvaguarda», RTSS (CEF), núm. 454 (2021), pp. 17-55.

9 Vid. J. F. Blasco LAHOZ, «Las medidas adoptadas en materia de protección social
} 
en tres grandes grupos: en primer lugar, la mejora de la protección por desempleo; en segundo, una acción protectora cualificada para los trabajadores que contraen Covid y, en tercer lugar, la creación del ingreso mínimo vital.

La protección por desempleo ha sido uno de los campos donde los esfuerzos del Gobierno han resultado más intensos con la aprobación de numerosas medidas de carácter coyuntural dirigidas a garantizar un ingreso a quienes han sufrido más directamente las consecuencias de la pandemia. El propósito no ha consistido en reformular la prestación o el subsidio por desempleo, sino en permitir que accedan a esos beneficios quienes se han encontrado en situación legal de desempleo debido al Covid. Son medidas que se pusieron en marcha en los primeros momentos del estado de alarma y cuyos destinatarios estaban perfectamente identificados, como se abordó en el artículo publicado en el núm. 2 (2019) de esta misma revista Foro. A modo de recordatorio, la protección por desempleo se dirigió, en primer lugar, a los afectados por ERTEs, bien fueran de suspensión o bien de reducción de jornada, con el fin de proporcionar los pertinentes ingresos sustitutivos. $\mathrm{Y}$ en segundo lugar, también disfrutaron de dicha protección, con carácter excepcional, aquellas personas que, por razones derivadas de la pandemia, se vieron en la imposibilidad de continuar prestando servicios por la dificultad intrínseca de encontrar trabajo en un contexto marcado por las restricciones a la movilidad y la notable disminución de la actividad económica. En ese escenario, se flexibilizaron las condiciones de acceso a la prestación por desempleo y se crearon prestaciones específicas - y extraordinarias- para colectivos concretos, como los artistas, los empleados de hogar ${ }^{10} \mathrm{o}$ los trabajadores temporales que no cumplían los requisitos para disfrutar de la prestación ordinaria, amén de medidas análogas en relación con los trabajadores autónomos que debieron cesar temporal o definitivamente la actividad. Alguna de esas acciones, por cierto, se incluye en la Ley 3/2021, de 12 de abril, por la que se adoptan medidas complementarias, en el ámbito laboral, para paliar los efectos derivados del Covid-19; norma extraña, quizá extemporánea, porque viene a recoger el contenido de reales decretos-ley aprobados en marzo de 2020 sin precisar suficientemente aspectos determinantes como su finalidad, función, vigencia y aplicabilidad un año después.

como consecuencia de la COVID-19», Trabajo y Derecho, monográfico núm. 12 (2020), disponible en www.smarteca.es.

${ }_{10}$ Vid. M. G. Aparicio Ruiz, «Medidas especiales en tiempos de Covid-19: la situación laboral de los empleados de hogar», Labos, vol. 1., núm. 3 (2020), pp. 69 y ss. 
Como también se indicó en el estudio precedente del que este es complementario, la Covid-19 debería ser considerada como enfermedad común, tanto la enfermedad en sí misma como un eventual aislamiento preventivo para evitar contagios, situación a la que por vía de interpretación administrativa se ha añadido la cuarentena obligatoria de quienes retornan a España desde determinados países ${ }^{11}$. Sin embargo, esas situaciones vinculadas al coronavirus, incluida la imposibilidad de desplazarse al trabajo ${ }^{12}$, han merecido la asimilación a contingencia profesional, lo que implica no solo la exención de esos requisitos de alta y cotización, sino también una mejora en el importe de la prestación de incapacidad temporal, que se eleva al 75 por 100 de la base reguladora frente al 60 por 100 inicial en situaciones de enfermedad común ${ }^{13}$. En esa misma línea, la Covid ha sido considerada también como contingencia profesional para el personal sanitario cuando se diagnosticó durante el mes siguiente a la finalización del estado de alarma, sin necesidad de demostrar una relación de causalidad con el trabajo, que se presume en estas situaciones ${ }^{14}$.

No obstante, es evidente que la medida más relevante desde la perspectiva de la seguridad es la creación de una nueva prestación que se incorpora al catálogo de la acción protectora del sistema con vocación de permanencia. En efecto, el denominado «ingreso mínimo vital» es una prestación estructural del sistema, a diferencia de las medidas contingentes y de emergencia para combatir los efectos del Covid. En verdad, el ingreso mínimo vital ya se encontraba en los planes del Gobierno, y así se había anunciado, pero la pandemia aceleró notablemente la puesta en marcha de una medi-

${ }^{11}$ Vid. Criterio de Gestión 10/2021, de 23 de abril, de la Subdirección General de Ordenación y Asistencia Jurídica del INSS.

${ }^{12}$ Vid. disposición adicional 21. ${ }^{a}$ del Real Decreto-ley 11/2020. El Real Decretoley 28/2020 asimiló al accidente de trabajo los «periodos de aislamiento, contagio o restricción en las salidas del municipio donde tengan el domicilio o su centro de trabajo las personas trabajadoras como consecuencia del virus Covid-19».

${ }_{13}$ Vid. Real Decreto-ley 6/2020, de 10 de marzo. Conviene precisar que el Real Decreto-ley $3 / 2021$, de 2 de febrero, dispuso que el «personal que preste servicios en centros sanitarios y sociosanitarios inscritos en los registros correspondientes que, en el ejercicio de su profesión, durante la prestación de servicios sanitarios o sociosanitarios haya contraído el virus SARS-CoV-2, dentro del periodo comprendido desde la declaración de la pandemia internacional por la Organización Mundial de la Salud hasta el levantamiento por las autoridades sanitarias de todas las medidas de prevención adoptadas para hacer frente a la crisis sanitaria ocasionada por el mencionado virus SARS-CoV-2, tendrá las mismas prestaciones que el sistema de la Seguridad Social otorga a las personas que se ven afectadas por una enfermedad profesional».

${ }^{14}$ Vid. art. 9 del Real Decreto-ley 19/2020, de 26 de mayo. 
da que ha nacido con cierta improvisación, como desde luego ha quedado de manifiesto en las reformas que ha sufrido su norma reguladora en muy corto espacio de tiempo y en las dificultades burocráticas que han ralentizado el reconocimiento y cobro de la prestación.

Sea como fuere, el ingreso mínimo vital fue creado por el Real Decretoley 20/2020, de 29 de mayo, y tiene como objetivo, en atención a su art. 1, «prevenir el riesgo de pobreza y exclusión social de las personas que vivan solas o integradas en una unidad de convivencia, cuando se encuentren en una situación de vulnerabilidad por carecer de recursos económicos suficientes para la cobertura de sus necesidades básicas». El ingreso mínimo vital, por consiguiente, se configura como una prestación no contributiva que de algún modo viene a completar y dar sentido al resto de prestaciones de esa índole, configurando, ahora sí, una auténtica modalidad no contributiva del sistema, con un campo de aplicación personal más ambicioso y acercándose a la universalidad subjetiva a la que debe tender la Seguridad Social por imperativo del art. 41 CE.

En términos muy resumidos, pues no es estrictamente una medida «antiCovid», el ingreso mínimo vital se dirige a personas de entre veintitrés y sesenta y cinco años (y también de otras edades cuando concurran razones ligadas a violencia de género, explotación sexual o trata de seres humanos), que podrán convertirse en beneficiarios si carecen de recursos suficientes, definidos en atención a unos umbrales de rentas más o menos generosos en función de si el interesado vive solo o se integra en una unidad de convivencia. En cuanto a la nacionalidad, es una prestación que puede ser reconocida tanto a españoles como a extranjeros, siempre que se encuentren en situación regular y hayan vivido en España durante un año.

Se trata de un marco normativo con cierta complejidad en su aplicación práctica, porque las reglas generales tienen excepciones, dado que todavía no se ha aprobado un desarrollo reglamentario que concrete aspectos dudosos y porque es necesaria una coordinación con las comunidades autónomas, que participan en la gestión y algunas de ellas contaban además con prestaciones similares.

En relación con el importe, la norma ha optado por configurar una cantidad mínima para el beneficiario que vive solo, pero susceptible de incremento cuando ese beneficiario forma parte de una unidad de convivencia con mayores necesidades. Sin perjuicio de elevaciones al alza en el futuro, la cuantía mensual del ingreso mínimo vital durante 2021 asciende a 469,93 euros (5.639,20 euros anuales), pero puede incrementarse en atención al número de convivientes y sus circunstancias concre- 
tas hasta 1.137,24 euros mensuales, amén de la posibilidad de percibir un complemento adicional en caso de familia monoparental.

\section{REGLAS SECTORIALES Y COLECTIVOS PARTICULARES}

La situación de emergencia derivada del Covid motivó actuaciones más concretas para resolver problemas suscitados en determinados sectores, principalmente en el empleo público. Como es sabido, la pandemia puso a prueba la capacidad y la fortaleza del sistema público de salud, y por ello desde marzo de 2020 se flexibilizaron los procedimientos para la contratación de personal sanitario ${ }^{15}$, permitiendo el reclutamiento de personas que todavía no habían obtenido el título necesario para poder realizar las tareas correspondientes o facilitando la compatibilidad con la pensión de jubilación del salario obtenido por los profesionales de la medicina y enfermería que excepcionalmente han reanudado la actividad para contribuir en la lucha contra el Covid ${ }^{16}$. Son medidas que no quedaron acotadas al primer estado de alarma, sino que se han extendido en el tiempo porque las bolsas de trabajo, tan características en el ámbito sanitario, por momentos se han $\operatorname{agotado}^{17}$. Y algunas medidas similares se han planteado en el ámbito de la docencia por la potencial falta de profesorado en un escenario de grupos más reducidos.

En el artículo precedente se dejó constancia de las numerosas medidas que se implementaron en sectores muy diversos, como el judicial, la formación profesional, el transporte por carretera o el ámbito agrícola, o de la ampliación excepcional de la cobertura de la prestación por desempleo. Son, por lo general, medidas que desaparecieron durante la denominada desescalada o, a más tardar, una vez transcurridos tres meses desde la finalización del estado de alarma decretado en marzo, y, por tanto, con un horizonte temporal que no debía exceder de septiembre de $2020^{18}$. Es cierto, no obstante, que esas actuaciones han podido contar con efectos de más amplio espectro, como sucede en general con el desempleo, y no solo

15 Vid. Órdenes SND/232/2020, de 15 de marzo, y 319/2020, de 1 de abril.

16 Vid. arts. 13 y 14 del Real Decreto-ley 8/2021, de 4 de mayo, por el que se adoptan medidas urgentes en el orden sanitario, social y jurisdiccional, a aplicar tras la finalización de la vigencia del estado de alarma declarado por el Real Decreto 926/2020, de 25 de octubre, por el que se declara el estado de alarma para contener la propagación de infecciones causadas por el SARS-CoV-2.

17 Vid. Real Decreto-ley 29/2020, de 29 de septiembre.

${ }^{18}$ En el ámbito de la Justicia, por ejemplo, vid. Orden JUS/504/2020, de 5 de junio. 
el vinculado a los ERTEs, sino también con prestaciones específicas para algunos sectores, como el cultural ${ }^{19}$, y con alguna ventaja ligada a las reglas de compatibilidad de las prestaciones por desempleo con el trabajo en el campo, que se extendió hasta el 30 de septiembre de 2020, pero conviene destacar que los extranjeros entre dieciocho y veintiún años que se acogieron a esta posibilidad disfrutarán de un permiso de residencia de dos años de duración, susceptible de renovación por otros dos años ${ }^{20}$. Además, en el terreno de la formación profesional el «aula virtual» se considera como formación presencial durante $2021^{21}$.

Asimismo, en relación con los extranjeros, el confinamiento provocó una problemática particular a causa de la suspensión de procedimientos administrativos que no permitía la renovación de las pertinentes autorizaciones para residir y trabajar. Para evitar incertidumbres, el Gobierno prorrogó automáticamente las autorizaciones y tarjetas de identidad — pues la medida afectaba a extranjeros, a ciudadanos de la UE y a los miembros de su familia- que expiraban durante el estado de alarma, y lo hizo con cierta generosidad, pues dicha prórroga se extendería durante los seis meses siguientes a la finalización de esa particular situación ${ }^{22}$.

En fin, dentro de estas medidas sectoriales destacan también otras de apoyo al empleo diferentes de los ERTE porque ya se ubican en un contexto en el que resulta evidente que las consecuencias de la pandemia tendrán efectos económicos a largo plazo y que inciden con mayor rotundidad en determinados sectores, como el turismo, toda vez que las restricciones de movilidad y la distancia social afectan muy notablemente a esa actividad económica. No resulta sorprendente, por tanto, que se aprobaran acciones específicas, en la forma de bonificaciones de cuotas a la Seguridad Social, para las empresas turísticas que generaron actividad productiva en los meses de julio, agosto, septiembre y octubre de 2020, incluidas las dedicadas al comercio y hostelería en ese sector del turismo ${ }^{23}$.

19 Vid. Real Decreto-ley 32/2020, de 3 de noviembre, por el que se aprueban medidas sociales complementarias para la protección por desempleo y de apoyo al sector cultural.

${ }^{20}$ Vid. Real Decreto-ley 19/2020, de 26 de mayo.

${ }^{21}$ Vid. Resolución de 18 de diciembre de 2020, del Servicio Público de Empleo Estatal, por la que se establecen, en su ámbito de gestión, medidas extraordinarias para hacer frente al impacto del Covid-19 en materia de formación profesional para el empleo en el ámbito laboral, para la iniciativa de formación programada por las empresas (BOE de 25 de diciembre).

22 Vid. Orden SND/421/2020, de 18 de mayo.

${ }^{23}$ Vid. Real Decreto-ley 25/2020, de 3 de julio. 


\section{LA DENOMINADA «NUEVA NORMALIDAD» ENTRE JUNIO Y OCTUBRE DE 2020}

Las cifras de contagios y fallecidos a causa del Covid se fueron reduciendo durante el mes de abril de 2020, el colapso sanitario se evitó y con ello se debilitó la justificación para el mantenimiento del estado de alarma y para la limitación que supone en los derechos fundamentales de las personas. El Gobierno, sin embargo, advirtió que desde un punto de vista sanitario resultaba contraproducente una finalización abrupta del estado de alarma y una recuperación completa de las libertades, toda vez que no existía en ese momento una vacuna ni un tratamiento completamente eficaz.

Desde la perspectiva del lenguaje se acuñan en ese momento los términos de «nueva normalidad» y «desescalada», en orden a clarificar que el tránsito desde el confinamiento a la recuperación de las libertades sería gradual («desescalada») y que una vez concluido ese proceso la situación no sería la misma que con anterioridad a la pandemia, al menos inmediatamente, sino que habrían de respetarse ciertas limitaciones para evitar rebrotes de la enfermedad, y de ahí que se aludiera a la «nueva normalidad».

El proceso de desescalada comenzó el 4 de mayo de 2020 mediante la implementación de un plan que constaba de cuatro fases por las que progresivamente, y de forma asimétrica, irían transitando los distintos territorios de España en atención al impacto de la enfermedad en cada uno de ellos. La situación del sistema sanitario constituía un punto de referencia determinante, pues el paso de una fase a otra dependía, entre otros factores, de que en caso de eventuales retrocesos la sanidad pudiera hacer frente a la situación sin riesgo de colapso.

Con esas cautelas, la denominada «fase 0 », de carácter preparatorio, se inició el 4 de mayo y tuvo una duración de una semana. Durante esa fase 0 se permitió la apertura de pequeños negocios, como, por ejemplo, peluquerías, pero debiendo adoptarse múltiples cautelas, como limitaciones de aforo, mayores medidas de higiene o atención exclusiva mediante cita previa ${ }^{24}$. La necesaria protección de trabajadores y de clientes conllevaba, asimismo, el uso obligatorio de mascarilla y la limpieza frecuente de

${ }^{24}$ Vid. Órdenes SND/388/2020, de 3 de mayo (bttps://www.boe.es/diario_boe/txt. php? $i d=B O E-A-2020-4793$ ) y SND/399/2020, de 9 de mayo (bttps://www.boe.es/eli) es/o/2020/05/09/snd399/con). 
manos con gel hidroalcohólico ${ }^{25}$. Todo ello sin perjuicio de que el teletrabajo seguía siendo considerado como la opción preferente para prestar servicios durante las fases 0 y $1^{26}$.

Tras esta «fase 0», por la que no transitaron algunas islas de Baleares y Canarias (Formentera, La Gomera, El Hierro y La Graciosa), que pasaron directamente a la fase 1 debido a la escasa incidencia del virus en esos lugares $^{27}$, se inició el proceso real de desescalada, pero no en todas las provincias y comunidades autónomas por igual. Mientras el 11 de mayo algunos territorios (como Madrid y Barcelona) permanecieron en fase 0, otros, los menos afectados, pasaron a la fase 1, en la que ya se permitió la apertura de las terrazas de los bares (no de la zona interior), pero con esas reglas sobre limitación de aforo, distancia social y hábitos de limpieza más intensos.

La fase 2 comenzaría el 18 de mayo en esas islas de Canarias y Baleares antes aludidas, y una semana después, el 25 de mayo, en las provincias y comunidades autónomas de la península con menos incidencia del Covid. En esta fase 2 ya se admitiría una mayor movilidad de las personas, con franjas horarias dedicadas a pasear o hacer deporte ${ }^{28}$, y cada vez con menos restricciones a la apertura de negocios, si bien las actividades de ocio con dificultades para mantener la distancia social seguirían restringidas, o directamente prohibidas, lo que afectaba principalmente a discotecas y gimnasios. Todo ello suponía una reincorporación de los trabajadores, pero de forma gradual, pues las actividades comerciales no operaban a pleno rendimiento y muchos trabajadores permanecían con su contrato suspendido en virtud del ERTE.

La fase 3 se inició el 1 de junio en las islas de Baleares y Canarias ya mencionadas ${ }^{29}$, y el 8 de junio en las provincias y comunidades autónomas de la península menos afectadas ${ }^{30}$. Desde luego, en todas estas fases se mantenía la restricción de movilidad entre unas partes y otras del territo-

25 Vid. Orden TMA/384/2020, de 3 de mayo, para el sector del transporte (https://www. boe.es/diario_boe/txt.php?id=BOE-A-2020-4789), y Orden JUS/394/2020, de 8 de mayo, para el sector de la justicia (bttps://www.boe.es/diario_boe/txt.php? id=BOE-A-2020-4897).

26 Vid. Orden SND/399/2020, de 9 de mayo (bttps://www.boe.es/eli/es/o/2020/05/09/ snd399/con).

${ }^{27}$ Vid. Orden SND/386/2020, de 3 de mayo (https://www.boe.es/diario_boe/txt. php? $i d=B O E-A-2020-4791)$.

${ }_{28}$ Vid. Orden SND/427/2020, de 21 de mayo (https://www.boe.es/diario_boe/txt. php? id =BOE-A-2020-5218).

${ }_{29}$ Vid. Orden SND/458/2020, de 30 de mayo.

${ }^{30} \mathrm{Vid}$. Orden SND/507/2020, de 6 de junio. 
rio español para evitar una propagación de la enfermedad, y la progresiva reanudación de la actividad económica debía hacer frente a variadas limitaciones, principalmente la de aforo en los establecimientos, imprescindible para garantizar el respeto a la «distancia social».

Tras la finalización de ese primer estado de alarma, el 21 de junio de 2020, subsistieron muchas de las limitaciones adoptadas durante el proceso de desescalada ${ }^{31}$. Las restricciones alcanzaban a la entrada en España, no admitida salvo excepciones, algunas de ellas vinculadas al contexto laboral, pues sí se permitía el acceso por motivos profesionales $(v \cdot g r$, trabajadores fronterizos o personal sanitario $)^{32}$. Estos límites se mantuvieron en términos más estrictos hasta 31 de diciembre ${ }^{33}$, y no se suprimieron tras esa fecha, sino que se establecieron controles particulares en la frontera con Portugal ${ }^{34}$, y se han ido configurando y levantando restricciones para ciertos países en función de la situación en cada uno de ellos ${ }^{35}$, como se precisará en el epígrafe siguiente. En cualquier caso, la entrada en España se condicionaba a determinados controles sanitarios para detectar contagios y prevenir la expansión del virus ${ }^{36}$.

No obstante, una de las mayores preocupaciones del Gobierno y los agentes sociales tras el fin del estado de alarma ha sido la reactivación económica y la recuperación de empleo, pues la destrucción de puestos de trabajo ha sido significativa. España se encontraba ya en una dinámica de ralentización de la economía antes del estado de alarma, con unos 3,2 millones de desempleados en febrero de 2020. Esa cifra se incrementó significativamente durante esta situación de emergencia, elevándose a 3,8 millones de personas en junio de 2020, y desde entonces se mantuvo estable (3,9 millones en abril de 2021), gracias, sin duda, a las sucesivas prórrogas de los ERTEs. La recuperación del empleo (muy evidente desde marzo-abril de 2021, pues en octubre ya se sitúa nuevamente en 3,2 millones de personas) depende de la reactivación de la economía, que no resultaba sencilla en ciertos ámbitos, como, por ejemplo, el turismo o la automoción. De ahí que el Gobierno y los agentes sociales llegasen a acuerdos para introducir estímulos económicos en esos sectores, además de algunos

${ }^{31}$ Vid. Real Decreto-ley 21/2020, de 9 de junio.

32 Vid. Orden SND/439/2020, de 23 de mayo.

33 Vid. Orden INT/1119/2020, de 27 de noviembre.

34 Vid. Orden INT/550/2020, de 21 de junio.

35 Vid. Orden INT/595/2020, de 2 de julio.

36 Vid. Resolución de 29 de junio de 2020, de la Dirección General de Salud Pública, Calidad e Innovación, relativa a los controles sanitarios a realizar en los puntos de entrada de España. 
$\operatorname{otros}^{37}$. El empeoramiento de la situación sanitaria desde finales de septiembre de 2020, que vino acompañado de nuevas restricciones, justificaba esa intervención.

\section{EL SEGUNDO ESTADO DE ALARMA «SANITARIO» EN OCTUBRE DE 2020: EN PARTICULAR, EL PAPEL DE LAS COMUNIDADES AUTÓNOMAS}

En junio de 2020 llegó a su fin el estado de alarma declarado en marzo y la positiva evolución de las cifras de contagiados y fallecidos despertó cierto optimismo. La «nueva normalidad» vino acompañada, incluso, de invitaciones al consumo y al turismo por parte de los responsables políticos. Sin embargo, esas buenas expectativas debieron enfrentarse a una realidad mucho más compleja a partir de finales de septiembre. La «nueva normalidad» dio paso a la denominada «segunda ola» — con «recidivas» posteriores, pues se han contabilizado cinco «olas» en España-, volviendo a generar riesgo de colapso del sistema sanitario en algunas regiones. En ese marco, mediante el Real Decreto 926/2020, de 25 de octubre, se inició otro estado de alarma, pero con una fisonomía muy particular y que quizá no encaja plenamente en los contornos de la Constitución, pues si bien las medidas sugeridas (confinamientos perimetrales, limitaciones de la libertad de reunión, incluso entre familiares, y «toque de queda») pudieran llegar a encajar entre los límites que admite el texto constitucional, lo cierto es que la capacidad última de decisión se atribuyó a las comunidades autónomas, lo que seguramente obligará al Tribunal Constitucional a pronunciarse ${ }^{38}$.

Sea como fuere, lo cierto es que las comunidades autónomas han contado con un papel protagonista en este contexto de la crisis sanitaria. En un primer momento, con la declaración inicial del estado de alarma en marzo de 2020, parecía que el Estado se arrogaba todas las competencias para la gestión de esta particular situación, pero pronto se comprobó que

37 Vid. Real Decreto-ley 25/2020, de 3 de julio, de medidas urgentes para apoyar la reactivación económica y el empleo.

38 Vid. I. García Vitoria, «El estado de alarma, los derechos fundamentales y los derechos laborales», Trabajo y derecho, núm. 12 (2020), disponible en www.smarteca.es. De hecho, en el momento de escribir estas líneas (octubre de 2021, fase de pruebas) el TC acaba de considerar incompatible con la Constitución ese segundo estado de alarma, lo que no resulta extraño, pues a idéntica conclusión llegó respecto del primero declarado en marzo de 2020. 
el Parlamento no concedería automáticamente todas las prórrogas que el Gobierno solicitara. El juego de las mayorías parlamentarias fue atribuyendo a las comunidades autónomas un mayor peso.

Por supuesto, en los albores del primer estado de alarma el propósito principal de las comunidades autónomas consistió en complementar la acción del Gobierno, procurando contribuir a la subsistencia de empresas y trabajadores. Las comunidades autónomas, con el objetivo de proteger el empleo y reactivar la economía, pusieron en marcha actuaciones de variada índole dirigidas, por ejemplo, a proporcionar financiación a las empresas y autónomos, a adaptar los planes de empleo a esta situación excepcional y a conceder ayudas para contribuir a la creación de empleo $^{39}$, ayudas, por cierto, que volvieron a cobrar protagonismo a finales de 2020 ante el incremento de la incidencia de la pandemia ${ }^{40}$ y que siguen aprobándose bien entrado $2021^{41}$. Asimismo, y con carácter complementario, también trataron de cubrir las lagunas del sistema de Seguridad Social a través de sus competencias de asistencia social y servicios sociales, generalizándose las prestaciones específicas dirigidas a trabajadores con rentas bajas afectados por ERTEs ${ }^{42}$ y, en general, a personas en situación de necesidad ${ }^{43}$.

El segundo gran grupo de medidas autonómicas tuvo que ver con las condiciones ligadas a la «nueva normalidad», pues muchas comunidades aprobaron una normativa específica que incluía reglas que incuestionablemente afectaban, o pueden afectar, a la dinámica de la prestación de trabajo, como el uso de mascarilla o la distancia social, que no solo tratan de proteger a los clientes, sino también a los trabajadores ${ }^{44}$.

39 Por ejemplo, Andalucía (Decreto-ley 10/2020, de 29 de abril); Baleares (Decretoley 8/2020, de 13 de mayo); Cataluña (Decreto-ley 16/2020, de 5 de mayo), y Extremadura (Decreto-ley 12/2020, de 19 de junio).

40 Por ejemplo, en Cataluña (Decreto-ley 39/2020, de 3 de noviembre) y en Canarias (Ley $4 / 2020$, de 26 de noviembre).

${ }^{41}$ V. gr. Ley de Cantabria 3/2021, de 26 de abril, de concesión de ayudas dirigidas a las empresas y las personas trabajadoras afectadas por expedientes de regulación temporal de empleo, para el sostenimiento del empleo y la actividad económica en el contexto de la crisis ocasionada por la pandemia de Covid-19.

${ }^{42}$ Así sucede, por ejemplo, en Valencia (Decreto-ley 3/2020, de 19 de abril), y Castilla y León (Decreto-ley 2/2020, de 16 de abril).

43 Por ejemplo, Baleares (Decreto-ley 4/2020, de 20 de marzo, y Ley 2/2020, de 15 de octubre); Canarias (Ley 3/2020, de 27 de octubre, y Decreto-ley 20/2020, de 26 de noviembre); Cataluña (Decreto-ley 14/2020, de 28 de abril, y Decreto-ley 21/2020, de 2 de junio), y Navarra (Decreto-ley Foral 3/2020, de 15 de abril).

${ }^{44}$ Por ejemplo, Aragón (Orden SAN/474/2020, de 19 de junio); Castilla-La Mancha (Decreto 24/2020, de 19 de junio), y Madrid (Orden 668/2020, de 19 de junio). 
En cualquier caso, la declaración del segundo estado de alarma en octubre de 2020 intensificó las competencias autonómicas, pues se configuró un estado de alarma asimétrico, con restricciones distintas en función del territorio. Por consiguiente, no en todas se decidió un cese de actividades no esenciales ni las restricciones a la movilidad fueron idénticas. Se trata, a la postre, de medidas de salud pública que inciden notablemente en la actividad económica. El final del estado de alarma el 9 de mayo de 2021 generó dudas jurídicas de envergadura sobre las competencias de las comunidades autónomas para continuar manteniendo esta clase de limitaciones, con posiciones encontradas de los tribunales a la espera de que el TS se pronunciase para unificar criterios ${ }^{45}$.

Lógicamente, el Gobierno central ha seguido aprobando medidas de distinto calado, pero ya no con la misma frecuencia e intensidad que en el tramo de marzo a junio de 2020. En verdad, durante este segundo periodo de alarma el Gobierno actuó en un segundo plano, con una función más discreta centrada en la coordinación y, quizá, en evitar que los conflictos de índole política pudieran perjudicar la eficacia de las medidas. Las «normas Covid» de origen estatal en la rama de lo social se limitaron a restricciones vinculadas con la entrada y salida de España ${ }^{46}$, que afectan principalmente a países no miembros de la $U^{47}$ y a los que se añadieron Reino Unido ${ }^{48}$, con previsiones particulares para Gibraltar ${ }^{49}$, Brasil,

45 Vid. art. 15 del Real Decreto-ley 8/2021, de 4 de mayo, por el que se adoptan medidas urgentes en el orden sanitario, social y jurisdiccional, a aplicar tras la finalización de la vigencia del estado de alarma declarado por el Real Decreto 926/2020, de 25 de octubre, por el que se declara el estado de alarma para contener la propagación de infecciones causadas por el SARS-CoV-2.

${ }_{46}$ Vid. art. 1 del Real Decreto-ley 8/2021, de 4 de mayo, por el que se adoptan medidas urgentes en el orden sanitario, social y jurisdiccional, a aplicar tras la finalización de la vigencia del estado de alarma declarado por el Real Decreto 926/2020, de 25 de octubre, por el que se declara el estado de alarma para contener la propagación de infecciones causadas por el SARS-CoV-2.

47 Vid. Orden INT/448/2021, de 10 de mayo, por la que se modifica la Orden INT/657/2020, de 17 de julio, por la que se modifican los criterios para la aplicación de una restricción temporal de viajes no imprescindibles desde terceros países a la Unión Europea y países asociados Schengen por razones de orden público y salud pública con motivo de la crisis sanitaria ocasionada por el Covid-19.

${ }^{48}$ Vid. Orden PCM/1237/2020, de 22 de diciembre, por la que se publica el Acuerdo del Consejo de Ministros de 22 de diciembre de 2020, por el que se establecen medidas excepcionales para limitar la propagación y el contagio por el Covid-19 mediante la limitación de los vuelos directos y buques de pasaje entre Reino Unido y los aeropuertos y puertos españoles. Esas limitaciones fueron prorrogadas por la Orden PCM/1295/2020, de 30 de diciembre.

$49 \mathrm{Vid}$. Orden INT/1236/2020, de 22 de diciembre, por la que se establecen criterios para la restricción temporal del acceso por vía terrestre al espacio Schengen a través del 
Sudáfrica ${ }^{50}$ o India ${ }^{51}$, por la especial virulencia de las variantes del Covid en dichos países, aunque conviene destacar también los nuevos protocolos y procedimientos que repercutirán en la contratación de trabajadores extranjeros precisamente para limitar los efectos de esa enfermedad ${ }^{52}$.

\section{A MODO DE CONCLUSIÓN: EL ALCANCE DE LA CAUSA COVID}

Como resulta comprensible, más bien inevitable dadas las circunstancias, las medidas aprobadas en el contexto Covid y las normas que las contienen no han sido fruto de un proceso de maduración o reflexión en el que se analizasen pormenorizadamente sus ventajas e inconvenientes, y por supuesto carecen de una planificación previa, porque son, innegablemente, normas de urgencia, más bien de emergencia, que no se preocuparon tanto por la precisión técnica o por articular correctamente su encaje en el conjunto del ordenamiento como por atender necesidades que en los albores de la crisis sanitaria se estimaban prioritarias frente a consideraciones de técnica legislativa, que quedaron relegadas a una posición insignificante entre las preocupaciones de los poderes públicos. De este modo, son normas que nacieron con defectos de técnica legislativa, no siempre coordinadas, con carácter aluvional y permanentemente expuestas a modificación para tratar de atender las necesidades más urgentes que se iban detectando.

En ese primer momento el Gobierno aprobó medidas de urgencia dirigidas a minimizar el impacto negativo de una situación que, en apariencia, no habría de durar demasiado tiempo ni alterar significativamente las perspectivas de crecimiento y prosperidad empresarial y económica. Dicho de

puesto de control de personas con el territorio de Gibraltar por razones de salud pública con motivo de la crisis sanitaria ocasionada por el Covid-19.

50 Vid. Orden PCM/439/2021, de 5 de mayo, por la que se publica el Acuerdo del Consejo de Ministros de 4 de mayo de 2021, por el que se prorroga el Acuerdo del Consejo de Ministros de 2 de febrero de 2021, por el que se establecen medidas excepcionales para limitar la propagación y el contagio por el Covid-19 mediante la limitación de los vuelos entre la República Federativa de Brasil y la República de Sudáfrica y los aeropuertos españoles.

${ }_{51}$ Vid. Orden SND/466/2021, de 13 de mayo, por la que se prorroga la Orden SND/413/2021, de 27 de abril, sobre las condiciones de cuarentena a las que deben someterse las personas procedentes de la República de la India a su llegada a España durante la situación de crisis sanitaria ocasionada por el Covid-19.

52 Por ejemplo, vid. art. 3 de la Orden ISM/1289/2020, de 28 de diciembre, por la que se regula la gestión colectiva de contrataciones en origen para 2021. 
otro modo, el estado de alarma se concebía como un breve paréntesis por motivos sanitarios, pero se estimaba, o así se anunciaba, que una vez controlados los efectos del virus la actividad económica e industrial se reactivaría en las mismas condiciones. Resulta ya evidente que las consecuencias del Covid provocarán efectos a largo plazo no deseados y completamente imprevistos en marzo-abril de 2020.

En efecto, el transcurso del tiempo ha derivado en otro escenario con muchas más incertidumbres tanto en el plano económico como en el social y jurídico. Las consecuencias han superado - negativamente- esas previsiones iniciales, de modo que los problemas pretendidamente coyunturales se han convertido ya en dificultades en muchos casos estructurales o a largo plazo. En ese nuevo marco, las previsiones económicas son cambiantes, máxime ante la incertidumbre sobre cuándo dejará el virus/enfermedad de constituir una amenaza tan intensa o en qué momento será posible retornar plenamente a los hábitos de vida y consumo previos a marzo de 2020.

Es cierto que las consecuencias hasta el momento no se han manifestado con toda su crudeza por las medidas implementadas para evitar una masiva extinción de contratos. La prohibición de despedir por causa Covid y, sobre todo, las ventajas de los ERTEs, con ahorro de cotizaciones para los empleadores y acceso a la prestación por desempleo para los trabajadores, han evitado hasta el momento un impacto más intenso sobre el mercado de trabajo. Pero la red de protección pública no podrá soportar indefinidamente esos costes, y, una vez que se debilite, será necesario arbitrar nuevas medidas.

En cualquier caso, la preferencia por los ERTEs, ligada a la «prohibición de despedir» por causa Covid, no puede esconder que la situación actual es ya muy distinta a la de marzo de 2020. En aquel momento era muy razonable no permitir que un empleador pudiera aducir la concurrencia de causas económicas, técnicas, organizativas o de producción a partir de las consecuencias del Covid, pues se entendía que esa era una situación coyuntural que no podía justificar medidas definitivas. Sin embargo, meses después una buena parte de los avatares empresariales y laborales están «relacionados» con la pandemia. En la mayor parte de los casos resulta imposible desligar las dificultades económicas u operativas de una empresa de la crisis sanitaria. De una u otra manera, todas las dinámicas comerciales, sociales, económicas, e incluso vitales, están hoy condicionadas por la enfermedad Covid y han variado para contener su expansión.

En esos términos, la distinción entre causa Covid y causa ETOP, como circunstancias completamente independientes, es ya ficticia, tanto desde 
una perspectiva económica como social y jurídica. La causa Covid ha dejado de ser coyuntural en muchos casos para provocar dificultades estructurales que encajarían sin dificultad en una causa ETOP. La labor de los tribunales será determinante, pues pueden apostar por una interpretación amplia o estricta de la causa Covid y, en definitiva, de la relación de causalidad. Lo cierto es que cuando una situación transitoria o coyuntural se cronifica pierde su carácter temporal y se convierte en indefinida, lo que obliga a modificar la perspectiva de aproximación. De este modo, que el Covid haya sido el origen de las dificultades no puede suponer que cualesquiera causas ETOP en el futuro deban entenderse relacionadas con esa enfermedad. Cuando el problema se convierte en estructural pierde esa vinculación con la Covid y adquiere entidad propia, conduciendo a la aplicación de la legislación ordinaria — estructural si se quiere- en detrimento de la más coyuntural y de emergencia. Ese tránsito hacia la legislación estructural provocaría consecuencias no totalmente predecibles, aunque muy probablemente negativas en términos de destrucción de empleo. En cualquier caso, mientras los ERTEs sigan prorrogándose seguramente las dificultades no se manifestarán en toda su intensidad. 